\title{
Education Without Borders: Exploring the Achievement of ABET Learning Outcomes through Engineers Without Borders-USA
}

\section{Kaitlin Litchfield, University of Colorado, Boulder}

Kaitlin Litchfield received her undergraduate degree in Civil Engineering at the University of New Hampshire and is currently pursuing a $\mathrm{PhD}$ at the University of Colorado Boulder in the Civil, Environmental and Architectural Engineering Department within the Mortenson Center for Engineering in Developing Communities. Her research interest is in recruiting, educating, and retaining engineers capable of meeting global development challenges, and her current work is focused on understanding engineers involved specifically with Engineers Without Borders-USA.

\section{Dr. Amy Javernick-Will, University of Colorado, Boulder}

Amy Javernick-Will is an Assistant Professor at the University of Colorado, Boulder in the Civil, Environmental, and Architectural Engineering Department. She received her Ph.D. from Stanford University and has focused her research efforts on knowledge mobilization in global organizations and projects and increasing diversity in engineering.

\section{Dr. Daniel Knight, University of Colorado, Boulder}

Dr. Knight is the Program Assessment and Research Associate for the Design Center (DC) Colorado at the University of Colorado Boulder. Dr. Knight supports the Center from a background in engineering education and applied psychology. Dr. Knight joined CU's College of Engineering and Applied Science in 2001 after graduate school. He has been a part time associate of DC Colorado since 2007, and became a full-time associate in August, 2013. Dr. Knight's responsibilities include assessment and program evaluation of the Center's hands-on design curriculum, educational research on center development, diversity and teamwork, and team facilitation for the Center's on-going industry-sponsored teams. Dr. Knight also serves as an educational resource for other departments in the College as well. 


\section{Education Without Borders: Exploring the Achievement of ABET Learning Outcomes through Engineers Without Borders-USA}

\section{Introduction}

Engineers of the future will be expected to obtain more skills, knowledge, and abilities in their education than ever before. Reports continue to expand lists of expected skills to include not only technical skills, but also professional, management, leadership, interdisciplinary, and global skills $\left(\right.$ e.g $\left.{ }^{1-4}\right)$. At the same time, undergraduate engineering programs are hard-pressed to fit additional credits in already overcrowded curricula. Within these constraints, extracurricular engineering activities have alleviated some of these competing demands. ${ }^{5}$ This research focuses on one such extracurricular activity, participation in Engineers Without Borders (EWB), a global humanitarian engineering service organization, in order to explore how such participation may influence learning outcomes.

Since the early 1990s, programs with some form of the name EWB have been established in multiple countries, including France, Belgium, Spain, Denmark, Sweden, Italy, Canada, and the USA. ${ }^{6}$ Through these organizations, both student and professional engineers have engaged in voluntary engineering service projects around the globe, often in foreign countries. Articles anecdotally report that these engineers gain professional skills including communication, interdisciplinary teamwork, systems thinking, cultural and societal awareness, and project management through these experiences. ${ }^{7-9}$ Although beliefs about the benefits of involvement with organizations such as EWB are well acknowledged, the field lacks empirical evidence to determine whether or not EWB members truly gain unique learning outcomes compared to their peers. In this study, we assess the self-perceived learning outcomes of one large EWB-USA student chapter in the American West in comparison to the learning outcomes of engineers not involved with the organization. Because engineers engage with EWB-type organizations in many countries around the world, this research sets a stage for continued international engineering education research into such organizations and their associated learning outcomes.

\section{Background}

Global challenges, such as those stated in the Millennium Development Goals ${ }^{10}$ and the Grand Challenges for Engineering, ${ }^{11}$ call for the engagement of engineers around the world. Meeting goals that include poverty reduction, access to safe drinking water and sanitation, affordable renewable energy, and improved healthcare all require the contribution of engineers; however, currently many engineering education programs fall short in preparing engineers with the necessary skill sets to do so. ${ }^{9}$ Skills in non-technical communication, understanding of societal impacts, systems' thinking, and cultural awareness must be included in an engineering education in order to prepare engineers to solve the most pressing global issues.

In previous work, the authors have shown that EWB-USA members identify holes in their engineering education that involvement with EWB-USA can fill. ${ }^{12}$ Educational gaps including hands-on experience and application, a global perspective, and project management were found to be widely expressed gains from organizational involvement. These findings align with 
multiple theoretical perspectives on how learning takes place, which we draw on for this research and discuss in the following paragraph.

Through participation with EWB-USA, engineers gain hands-on experience in a complete project from conceptualization through monitoring and evaluation. Active members often travel to project sites on multiple occasions to assess, implement, and test designs; and they are involved with fund-raising, teamwork, professional mentoring, and public communication throughout the process. Skills in design experience, project management, leadership, societal awareness, etc. can be acquired naturally through this experience. As Kolb's theory of experiential learning explains, "Learning is the process whereby knowledge is created through the transformation of experience."13 As EWB-USA members go through their design process, learning takes place through the iterative, holistic design experience. Similarly, Lave and Wenger's theory of situated learning expresses that learning occurs through participation in a community of practice. ${ }^{14}$ Both of these theories help explain why engagement in an activity such as EWB would potentially assist engineers' learning. This research relies on these frameworks for how learning takes place to provide evidence for the learning outcomes from EWB-USA.

Due to the anecdotal evidence and learning theories that suggest increased learning can take place through experiences like those found in EWB, we sought to understand whether engineers involved with EWB-USA perceive themselves to have greater learning outcomes than engineers not involved with the organization. Therefore, we hypothesized that:

(Hypothesis 1) Engineers involved with EWB-USA will perceive greater learning outcomes than engineers not involved with the organization.

In addition, we hypothesized that:

(Hypothesis 2) Findings will be more significant for active participants of EWB-USA and similar organizations than for engineers who do not actively participate in EWB-USA or a similar organization.

\section{Methods}

To assess these hypotheses, we developed a survey questionnaire administered to engineering students at the University of Colorado, Boulder and compared perceived learning outcomes between different groups of respondents.

\section{Item Selection}

Learning outcome items included on the survey came from the Center for the Advancement of Scholarship on Engineering Education (CASEE). ${ }^{15}$ Their report developed 62 survey items to assess ABET learning outcomes, which includes items to assess the traditional a-k outcomes ${ }^{16}$ as well as items to assess their four suggested additional outcomes ("l-o"). Figure 1 shows the list of all fifteen outcomes.

We chose to keep the same style of questions and response options as CASEE. All of the survey items used a Likert-type scale. Twelve of the fifteen outcomes asked "please rate your ability to do the following:" on a five-point scale from no ability to high ability. Two outcomes (i \& n) asked "to what extent do you/are you:" on a four-point scale from not at all to always. Outcome 'o' asked "how often:" with a four-point scale from almost never to almost always. 
In order to reduce the size of the survey, we decreased the number of items from 62 to 45 by eliminating similar items, ensuring that each outcome had at least two items. In addition, because the final version of the survey is intended to reach both engineering students and practicing engineers, we revised items to be applicable to both audiences. In some cases wording was changed to broaden the question without altering the meaning, for example items in outcome 'o' originally asked, "in your engineering courses, how often:" [do you do the following]. We rephrased this question to say, "in your engineering work, how often:" [do you do the following]. The final items were written into Qualtrics survey software for distribution.
(a) an ability to apply knowledge of mathematics, science, and engineering,
(b) an ability to design and conduct experiments, as well as to analyze and interpret data,
(c) an ability to design a system, component, or process to meet desired needs within realistic constraints such as economic, environmental, social, political, ethical, health and safety, manufacturability, and sustainability,
(d) an ability to function on multidisciplinary teams,
(e) an ability to identify, formulate, and solve engineering problems,
(f) an understanding of professional and ethical responsibility,
(g) an ability to communicate effectively,
(h) the broad education necessary to understand the impact of engineering solutions in a global \& societal context,
(i) a recognition of the need for, and ability to engage in, lifelong learning,
(j) a knowledge of contemporary issues;
(k) an ability to use the techniques, skills, and modern engineering tools necessary for engineering practice,
(l) an ability to manage a project, including a familiarity with business, market-related, and financial matters,
(m) a multidisciplinary systems perspective,
(n) an understanding of and appreciation for the diversity of students, faculty, staff, colleagues, and customers, (o) a strong work ethic.

\section{Figure 1: List of ABET Learning Outcomes a-o ${ }^{15}$}

\section{Data Collection}

The survey was sent to 5,275 students within the engineering college at the University of Colorado, Boulder. This population of students was chosen for ease of access and because EWB-USA was founded at this school in 2001, helping to form its large student EWB-USA membership, which would provide a sizeable data set for our analysis.

Each student received a personalized link to the survey through their school email via Qualtrics. The survey was left open for 19 days, and any student who had not participated after two weeks was sent a reminder email. Of the 583 students who completed the survey (11\% response rate), 566 final respondents were included in the analysis. Seventeen respondents were removed because they either did not complete a majority of the learning outcomes questions or they indicated that they were not an engineering major.

\section{Data Analysis}

Items within each of the fifteen outcomes were combined using the respondent's median score to give an overall score for each learning outcome. We then compared these scores among two different pairs of respondents using Mann-Whitney $U$ tests of comparisons. In addition to testing each learning outcome, outcomes were grouped by technical skills, broad skills, and holistic skills (similar to IJSLE ${ }^{8}$ ) and tests of comparison were run on the medians of these aggregated 
scores. While analysis of non-experimental quantitative data limits our ability to make direct causal claims about the effect of EWB involvement on learning outcomes, it can show associations between involvement and learning outcomes to encourage further research.

The first two groups that were compared were those who explicitly expressed membership in EWB-USA and those who did not. We called this the "EWB" comparison. As with any organization, official membership status does not necessarily indicate participation. Therefore, we created a second pair of groups for comparison called "EWB-like" in order to capture participants within EWB-USA and similar humanitarian engineering service organizations. Within this comparison, one group was comprised of those participants who indicated limited, moderate, or extensive active participation within EWB-USA or an organization or program similar to EWB-USA, and the other group was those who were neither active nor involved. To determine if a respondent was involved in an organization was similar to EWB-USA, participants were directly asked if they were involved with an organization or program similar to EWB-USA and if so, to write in the name of the program or organization. The authors read through individuals' responses, and those who listed humanitarian engineering service organizations or educational programs with a humanitarian engineering focus (e.g. Engineers for a Sustainable World, Bridges to Prosperity) were added to the EWB-like group.

In order to check whether or not increased learning gains were due to active participation in a professional engineering organization rather than humanitarian engineering participation, we ran two additional tests of comparison. The first test compared only EWB-like respondents by dividing respondents into "active" and "non-active" participants. Those in the active category indicated moderate or extensive active involvement with EWB-USA or a similar organization/program. The second test compared only non-EWB-like respondents divided into the same active and non-active categories. These comparisons allowed us to investigate active participation as a potentially spurious variable and make more accurate claims about the role of humanitarian engineering service involvement in broadening engineers' education.

\section{Results}

Of the 566 respondents, 51 (9\% of total) indicated EWB-USA membership. Of the 51 EWBUSA members, 40 (78\% of EWB-USA members) were active enough to move into the EWBlike group, and 23 non-EWB members were added to make 63 EWB-like respondents. Results from the Mann-Whitney U tests of comparison are shown in Table 1 below for both comparison groups. Each of the 15 a-o outcomes are listed individually and are grouped by their skill type (technical, broad, or holistic). For space reasons, we focus on results aggregated by skill type.

\section{Technical Skills}

Differences in self-perceived technical skill abilities were significant only in the comparison of EWB members with non-members to a p-value of 0.086 where non-EWB members indicated higher perceived technical skills. This difference in technical skills decreased for the EWB-like comparison. One reason that this difference may have decreased for this second comparison could be from an increase in graduate students and upperclassmen in the EWB-like group compared to the EWB member group, which would increase the average respondents' exposure to more technical classes and therefore perceived technical ability. 
Table 1: Results from Mann-Whitney $U$ tests of comparisons (p-values)

\begin{tabular}{|c|c|c|c|}
\hline Learning Outcome & No. of Items & EWB vs. Non-EWB ${ }^{a}$ & EWB-like vs. Non-EWB-like ${ }^{b}$ \\
\hline Technical Skills & 13 & $0.086^{*}$ & 0.432 \\
\hline a: Apply knowledge & 3 & 0.193 & 0.384 \\
\hline b: Experiments \& data & 4 & 0.979 & 0.539 \\
\hline e: Solve problems & 3 & $0.088 *$ & 0.851 \\
\hline $\mathrm{k}$ : Use skills & 3 & $0.004 * * *$ & $0.053 *$ \\
\hline Broad Skills & 26 & 0.634 & $0.007 * * *$ \\
\hline d: Multi-discip. teams & 3 & 0.332 & 0.224 \\
\hline f: Ethics & 3 & 0.572 & $0.100 *$ \\
\hline $\mathrm{g}:$ Communication & 3 & 0.796 & $0.083 *$ \\
\hline i: Lifelong learning & 3 & 0.436 & 0.283 \\
\hline $\mathrm{j}$ : Contemporary issues & 3 & 0.341 & $0.002 * * *$ \\
\hline 1: Manage \& finance & 4 & 0.413 & $0.040 * *$ \\
\hline $\mathrm{n}$ : Diversity appreciation & 4 & 0.592 & 0.754 \\
\hline o: Work ethic & 3 & 0.765 & 0.389 \\
\hline Holistic Skills & 7 & 0.629 & $0.062 *$ \\
\hline c: System to meet needs & 3 & $0.072 *$ & 0.904 \\
\hline h: Understand impact & 2 & 0.495 & $0.000 * * *$ \\
\hline m: Multi-discip. systems & 2 & 0.837 & $0.081 *$ \\
\hline
\end{tabular}

\section{Broad Skills}

Highly significant differences in broad skills were found for the EWB-like comparison in which respondents within the EWB-like group were higher than their non-EWB-like counterparts. Differences in broad skills were not significant in the EWB-USA member comparison. Looking at the specific learning outcomes listed under the broad skills category, EWB-like respondents showed the largest differences in their perceived knowledge of contemporary issues and their ability to manage a project (outcomes $\mathrm{j}$ and $\mathrm{l}$ ). Although results for individual survey items are not shown in Table 1, items about managing conflict on teams, identifying ethical dilemmas in engineering, conveying ideas in formal presentations, improving designs beyond submission, and completing team tasks on time were also significantly higher for the EWB-like respondents.

\section{Holistic Skills}

Similar results were found for holistic skills in which the EWB-like respondents showed significantly higher perceived skills and the EWB-USA members did not. Non-EWB-USA members showed significantly higher ability to design a system to meet needs (outcome c), which is similar to the outcomes in the technical skills. The EWB-like group did not show higher ability in outcome c; however, these respondents showed higher ability to understand the impact of their design and to take a multidisciplinary systems' perspective.

\section{Active and Non-active Comparisons}

In order to test whether or not the significant differences shown in Table 1 may be confounded by students' active participation in any professional engineering organization, we separated both the EWB-like and the non-EWB-like groups into two separate groups, active and non-active. Within the 63 EWB-like respondents, 45 (71\%) were active and $18(29 \%)$ were non-active. Of the 503 non-EWB-like respondents, 37 (7\%) were active and 466 (93\%) were non-active. 
Table 2 shows the results from the Mann-Whitney U tests of comparisons for both the EWB-like and non-EWB-like comparisons of active and non-active members. For both comparisons, all significant results were found to be higher for active respondents. Three learning outcomes-(i) lifelong learning, (j) contemporary issues, and (m) a multi-disciplinary perspective - showed significant differences across both comparisons. These findings indicate that these three learning outcomes may be due to active participation in a professional engineering organization rather than from EWB-like participation. Three learning outcomes-(e) ability to solve problems, (d) ability to work on multi-disciplinary teams, and (h) understanding the impact of work - along with the aggregated scores for broad and holistic skills - showed significant differences for the active EWB-like comparison and not for the non-EWB-like comparison. These findings indicate that being active within an EWB-like organization may be an important factor in achieving these specific learning outcomes through an EWB-like organization.

Table 2: Results from Mann-Whitney $U$ tests of comparisons for active vs. non-active respondents (p-values)

\begin{tabular}{|lcc|}
\hline \multicolumn{1}{|c}{ Learning Outcome } & EWB-like & Non-EWB-like $^{\mathbf{a}}$ \\
\hline Technical Skills & 0.194 & 0.689 \\
\hline a: Apply knowledge & 0.903 & 0.974 \\
b: Experiments \& data & 0.127 & 0.348 \\
e: Solve problems & $0.045^{* *}$ & 0.812 \\
k: Use skills & 0.937 & 0.292 \\
\hline Broad Skills & $0.083^{*}$ & 0.102 \\
\hline d: Multi-discip. teams & $0.035^{* * *}$ & 0.433 \\
f: Ethics & 0.256 & 0.619 \\
g: Communication & 0.784 & 0.429 \\
i: Lifelong learning & $0.053^{*}$ & $0.096^{*}$ \\
j: Contemporary issues & $0.035^{* *}$ & $0.067^{*}$ \\
l: Manage \& finance & 0.368 & $0.016^{* *}$ \\
n: Diversity appreciation & 0.472 & 0.327 \\
o: Work ethic & 0.537 & 0.800 \\
\hline Holistic Skills & $0.017^{* *}$ & 0.162 \\
\hline c: System to meet needs & 0.404 & 0.925 \\
h: Understand impact & $0.007^{* * *}$ & 0.133 \\
m: Multi-discip. systems & $0.051^{*}$ & $0.004^{* * *}$ \\
\hline *p<0.1; **p<0.05; ***p<0.01 & \\
a: All significant results are higher for active respondents \\
\end{tabular}

\section{Discussion}

The results show that EWB-USA members perceive themselves to have lower technical skills than their peers, which aligns with what we might expect given EWB-USA's focus on a more holistic approach to engineering projects. A typical EWB-USA project includes following a project through from inception and assessment to evaluation and monitoring. Along the way members must consider cross-cultural, economic, environmental, and social issues in addition to the technical design challenges. Because of their focus and work in the broader context of engineering, the EWB-USA members may not perceive their technical skills to be as strong as their peers. In addition, age may also be a confounding factor here where EWB-USA and EWBlike groups are significantly younger than their corresponding "non" groups. We note, however, that additional explanations about the perceptions of lower technical skills may exist. For 
instance, these members may have personality differences that cause this difference. This should be investigated in future research.

In light of EWB-USA's inclusion of more broad and holistic skills, the lack of significant differences in these skillsets between those involved with EWB-USA and those that were not involved were surprising. However, as with many organizations, membership does not necessarily indicate participation. Therefore, the EWB-like results may give a more accurate picture of learning outcomes achieved through humanitarian engineering service involvement because it accounts for respondents who are involved with EWB-USA or a similar organization, and it removes respondents who claimed to have no active participation in such an organization. In the EWB-like comparison, the differences in broad and holistic skills become more significant, especially in areas such as knowledge of project management, contemporary issues, understanding the impact of design, and taking a multidisciplinary systems perspective.

Because learning outcomes theoretically increase with age, and because the EWB and EWB-like groups were significantly younger than their respective comparison groups, the findings of higher perceived broad and holistic skills in these groups provide additional evidence for the benefit of involvement on professional learning outcomes. Another possible confounding variable was GPA, where higher GPA's would be associated with stronger learning outcomes; however, there were no significant differences in tests of mean GPA's between groups.

When considering the results from Table 1 alongside the results from Table 2, some of the significant differences found between EWB-like respondents and non-EWB-like respondents may be partially due to being active in a professional engineering organization in general. Particularly, lifelong learning, understanding contemporary issues, and taking a multidisciplinary systems' perspective are three outcomes which may be influenced by general professional engineering organization participation. It makes sense that professional organizational involvement would foster these outcomes through networking opportunities, lecture series, newsletters, and journals that often come with participation.

Again, considering Tables 1 and 2 together, there were three learning outcomes-(f) ethics, (g) communication, and (l) management and finance - that showed significant differences for EWBlike and non-EWB-like respondents yet did not show significant differences in the active and inactive comparisons. These results may indicate that these three learning outcomes in particular can be partially achieved through EWB-like participation. It may also be the case that these are skills which EWB-like participants begin their involvement with higher levels than their peers; however, our data cannot differentiate these potential causes. Future work will be needed to distinguish between the two possibilities.

\section{Conclusion}

In response to our first hypothesis, EWB-USA members did not perceive themselves to have greater learning outcomes than engineers not involved with the organization. In fact, they perceived themselves to have less technical skills. This comparison, however, may have been confounded by inactive members or engineers involved in similar organizations. Therefore, in response to our second hypothesis, findings showed that engineers active within EWB-USA and 
similar organizations perceived themselves to have greater broad and holistic skills than engineers not active within these organizations, particularly in areas of ethics, communication, and management and finance. Limitations of this work include the use of self-perceptions as assessment measures and the lack of causal proof associated with non-experimental quantitative studies. Future work can strengthen these findings through the use of more robust analyses such as regression modeling to control for potentially spurious variables such as age. Future work can also expand this study to international EWB organizations and other similar organizations, which are known to exist across the globe. The findings presented here support the belief that active participation in humanitarian engineering organizations such as EWB contributes to achieving professional learning outcomes needed to help prepare engineers to face global challenges.

\section{Acknowledgements}

This material is based in part upon work supported by the National Science Foundation Research in Engineering Education program under Grant No. 1129178. Any opinions, findings, and conclusions or recommendations expressed in this material are those of the authors and do not necessarily reflect the views of the National Science Foundation.

\section{References}

1. National Academy of Engineering. The Engineer of 2020: Visions of Engineering in the New Century. Washington, DC: National Academies Press; 2004.

2. Duderstadt JJ. Engineering for a Changing World: A Roadmap to the Future of Engineering Practice, Research, and Education. Ann Arbor, MI: The University of Michigan; 2008.

3. Sheppard SD, Macatangay K, Colby A, Sullivan WM. Educating Engineers: Designing for the Future of the Field. The Carnegie Foundation for the Advancement of Teaching; 2008.

4. American Society for Engineering Education. Innovation with Impact: Creating a Culture for Scholarly and Systematic Innovation in Engineering Education. Washington, D.C.; 2012 Jun.

5. Hartman H, Hartman M. Undergraduate Women's Participation in Professional Organizations. J Women Minor Sci Eng. 2005;11(2):117-37.

6. Schneider J, Lucena J, Leydens JA. Engineering to Help: The Value of Critique in Engineering Service. IEEE Technology and Society Magazine. 2009;28(4):42-8.

7. Amadei B, Sandekian R. Model of Integrating Humanitarian Development into Engineering Education. J Prof Issues Eng Educ Pract. 2010 Apr;136:84-92.

8. IJSLE: Humanitarian Engineering and Social Entrepreneurship. Convergence: Philosophies and Pedagogies for Developing the Next Generation of Humanitarian Engineers and Social Entrepreneurs. United States of America: IJSLE; 2012.

9. UNESCO. Engineering: Issues, Challenges and Opportunities for Development. France: UNESCO; 2010.

10. United Nations. United Nations Millennium Development Goals [Internet]. Millennium Goals. 2013 [cited 2013 Oct 2]. Available from: http://www.un.org/millenniumgoals/

11. Wulf WA. Great Achievements and Grand Challenges. The Bridge. 2000;30(3 \& 4):5-10.

12. Litchfield K, Javernick-Will A. Investigating Gains from EWB-USA Involvement. J Prof Issues Eng Educ Pract. 2013;140(1).

13. Kolb DA. Experiential Learning: Experience as the Source of Learning and Development. Englewood Cliffs, NJ: Prentice Hall; 1984.

14. Lave J, Wenger E. Situated Learning: Legitimate peripheral participation. Cambridge: Cambridge University Press; 1991.

15. Center for the Advancement of Scholarship on Engineering Education. Measuring Student and Faculty Engagement in Engineering Education. Washington, DC: National Academy of Engineering; 2005.

16. ABET. Criteria for Accrediting Engineering Programs, 2012 - 2013 [Internet]. 2011 [cited 2013 Sep 16]. 